\title{
COATING THICKNESS EVALUATION BY THERMOGRAPHIC APPARENT EFFUSIVITY METHOD
}

\author{
${ }^{1}$ Alexey MOSKOVCHENKO, ${ }^{2}$ Michal ŠVANTNER, ${ }^{3}$ Lukáš MUZIKA, ${ }^{4}$ Šárka HOUDKOVÁ \\ New technologies - research center, University of West Bohemia, Pilsen, Czech Republic, EU, \\ 1alexeym@ntc.zcu.cz, ${ }^{2}$ msvantne@ntc.zcu.cz, ${ }^{3}$ muzika@ntc.zcu.cz, ${ }^{4}$ houdkov@ntc.zcu.cz
}

https://doi.org/10.37904/metal.2021.4181

\begin{abstract}
Active thermography is a method for nondestructive inspection of materials. This contribution presents quantitative inspection of coating thickness by flash-pulse thermographic inspection and apparent thermal effusivity based evaluation. The apparent thermal effusivity algorithm for evaluation and visualisation of coating thickness is presented. The algorithm is based on a threshold value of the apparent effusivity, which can be found for any couple of substrate and coating if their effusivities differ. The square root of time at which the apparent effusivity curve reaches this threshold is then proportional to the thickness of the coating. Effectivity of the method is demonstrated by numerical model and experimental data obtained by inspection of $\mathrm{Cr} 13 \% \mathrm{Fe}$ thermally sprayed coatings made by twin wire arc spaying technology. A linear dependence between square root of apparent effusivity threshold time and couating thickness was found. Influence of the pulse length and presence of defects on the results are studied.
\end{abstract}

Keywords: Flash pulse thermography, coating thickness, apparent effusivity, thermographic inspection

\section{INTRODUCTION}

Coatings are covering layers applied to a surface of a material, which is also called a substrate. Different kinds of coatings are widely used for constructions protection against corrosion and wear, for a restoration, of for an enhancement of their life span [1,2]. There are a lot of types of coatings with different purposes, materials and application procedures. Coating thickness and its homogeneity are one of very important parameters for the evaluation of its quality and service life. Thus nondestructive methods of coating thickness determination are required for both manufacturing and exploitation of materials with coatings. Various nondestructive methods allowing coating thickness determinations were developed, e.g. methods based on eddy-current, x-ray, ultrasound, terahertz, etc. [3,4]. All of them have advantages and limitations. For instance, Eddy-current and ultrasound methods are contacted, X-ray may be not applicable by the safety rules, terahertz testing requires bulky and expensive equipment.

Active infrared thermography is a non-destructive, non-contact and fast inspection method, thus it is a prospective alternative to the commonly used methods [5]. It is based on external heating of a tested object and a subsequent analysis of its thermal response. Active thermography methods can be sorted in respect of heating source and heating procedure [6].

Various active thermography testing procedures and data processing algorithms were developed for coating thickness evaluation by infrared thermography [7]. Thermal contrast methods [8] require a reference area and these methods are suitable for defects detection but mostly not for coating thickness quantification. Pulsedphase and lock-in thermography allow to find a correlation between phase angle and coating thickness, but these dependencies are usually complicated like 4 order polynomial [9]. Analysis of the second logarithmic derivation [10] is enough sensitive and there is clear thickness-peak derivation time dependency. However, noises, finite heating time and polynomial fitting required for this method may cause distortion of temperature 
evolution and significantly shift peaks of derivatives or add other peaks on the derivative curve. Different processing techniques are compared for example in [11]. It is shown that time-power transformation has better sensitivity for coating thickness measurement. However, processing techniques as time-power or PCA are not based on physical model and results may be affected by number of factors.

The goal of this study was to create a thermographic coating thickness quantification method based on the analytical heat transfer model. Flash-pulse thermography and the apparent thermal effusivity evaluation method [12,13] were used for coating thickness measurement. The used method is based on the physical model and measurement of material thermal properties [14]. It is reference-free, sensitive and applicable for a wide range of coating end substrate material.

\section{METHODOLOGY}

Surface temperature of semi-infinite body after heating can be expressed as:

$T(0, t)=\frac{Q_{0}}{\sqrt{\rho C k \pi t}}$,

Where $Q_{0}$ is energy density deposited by the illumination at the surface, $\alpha$ is thermal diffusivity $\left(\mathrm{W} / \mathrm{m}^{2}\right), \rho$ is density $\left(\mathrm{kg} / \mathrm{m}^{3}\right), C$ is heat capacity $(\mathrm{J} /(\mathrm{kg} \cdot \mathrm{K})), k$ is thermal conductivity $(\mathrm{W} /(\mathrm{m} \cdot \mathrm{K})), z$ is coordinate $(\mathrm{m}), \sqrt{\rho C k}$ is also known as thermal effusivity of material $e\left(\mathrm{~W} \cdot \mathrm{s}^{1 / 2} /(\mathrm{m} 2 \cdot \mathrm{K})\right)$ and $t$ is time $(\mathrm{s})$. Thermal effusivity of semi-infinite body heated with Dirac pulse may be found from equation (1) as:

$e=\frac{Q_{0}}{T(0, t) \sqrt{\pi t}}$,

Plot $e(t)$ for the semi-infinite body is a strict line parallel to the $x$-axis illustrates the thermal effusivity of material (Figure 1). In the case of two-layer material:

$T(0, t)=\frac{Q_{0}}{e \sqrt{\pi t}}\left(1+2 \sum_{n=1}^{+\infty}\left(-\Gamma^{n}\right) \exp \left(-\frac{n^{2} L^{2}}{k t}\right)\right)$

where $L-$ is the thickness of the first layer $(\mathrm{m})$ and $\Gamma-$ is the reflection coefficient.

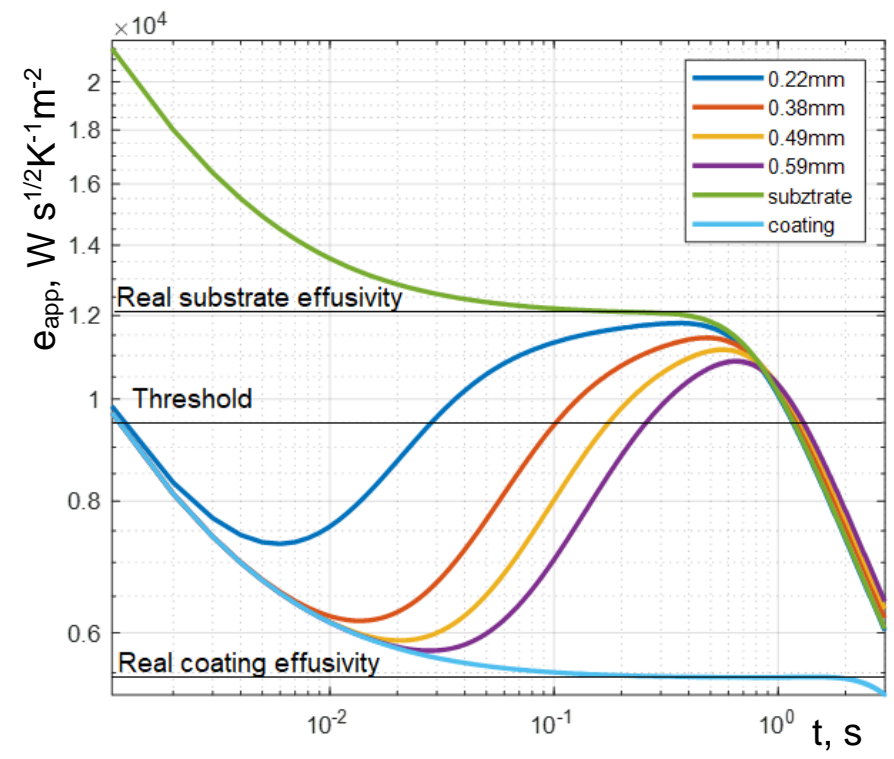

Figure 1 Example of effusivity curves for different coating thickness.

Since absorbed energy is hard determining by infrared testing the apparent thermal diffusivity algorithm was developed [13]. The apparent thermal effusivity can be obtained for each pixel of the infrared thermographic sequence. 
$e_{\text {app }}(L, t)=\frac{1}{T(L, t) \sqrt{t}}$,

Non-stationary heat conduction is the process of diffusion of thermal energy. Deeper material layers appear on the body surface with greater time delays. The same phenomenon can be observed by analyzing the timeevolution $e(t)$. As illustrated in (Figure 1), the initial section of the $e(t)$ curve represents the thermal effusivity of the coating material, and then, after a certain transition period, it goes to the substrate thermal effusivity. The inflection point in the $e(t)$ curve corresponds to the depth of the first layer and the ratio between the thermal properties of the coating and substrate. Hence, coating thickness can be evaluated by analyzing the corresponding inflection points. If the absorbed energy is unknown, the effusivity $e(t)$ can be replaced by the apparent effusivity $e_{\text {app }}(t)$ characterized by the same time behavior.

It has been presented in [14] that variations in coating thickness lead to a simple translation of the effusivity curve along the time axis (in the logarithmic representation). Hence, the apparent effusivity curve for any coating-substrate structure (Figure 1) crosses a particular value between the coating and substrate effusivities, while variations in coating thickness shift the time point of this intersection. In this study, the use of so-called threshold time $t_{t}$ is suggested. Such threshold time corresponds to the point where the effusivity curve crosses a particular threshold value located between the values of the coating and substrate effusivities. The $t_{t}$ values and their relationship to coating thickness can be found either experimentally or by modeling of particular test situations.

\section{EXPERIMENTAL SETUP}

The experimental sample was $4.91 \mathrm{~mm}$ thick steel plate (a substrate) with a Cr13\%Fe coating layer. The substrate was made from a S235 construction steel, which thermal conductivity was assumed to be in the range from 40 to $50 \mathrm{~W} \cdot \mathrm{m}^{-1} \cdot \mathrm{K}^{-1}$. The coating was produced by twin-wire arc spraying (TWAS) technology [15]. These coatings are characterized by high heterogeneity, high amounts of porosity, oxide inclusions, and intersplat boundaries. Their expected thermal conductivity is in the range from 2 to $10 \mathrm{~W} \cdot \mathrm{m}^{-1} \cdot \mathrm{K}^{-1}$. Coatings of four thicknesses were deposited on the substrate: $0.22,0.38,0.49$ and $0.59 \mathrm{~mm}$ (data was provided by the manufacturer of the samples).

A pulsed heating of the sample was performed by a single Hensel EH Pro 6000 flash lamp of the power about $6 \mathrm{~kJ}$ and pulse length $6 \mathrm{~ms}$. A thermographic record of the cooling process was captured by a FLIR A6751 IR camera by the frame rate of $400 \mathrm{~Hz}$, the length of the record was 2000 frames. The measurement setup and the principle of synchronization between the flash-lamp and camera were described in detail in [11]. Background subtraction and median filter with a $3 \times 3$ spatial mask were applied to all IR thermograms in the captured sequence before further processing.

\section{RESULTS AND DISCUSSION}

The temperature evolutions were averaged with a $50 \times 50$ mask for each coating thickness and processed by applying equation (4) for the calculation of apparent effusivity evolutions. The apparent effusivity for different coating thickness is shown in (Figure 2 a). The curves obtained show that the experimentally determined apparent effusivity values increase from lower to higher values at the beginning of the process. If the effusivity threshold is set, than a time of crossing this threshold $t_{t}$ can be obtained for every curve. Then the defect depth to square root of time linear dependancy can be obtained. Figure $\mathbf{2} \mathbf{b}$ illustrates $\sqrt{t_{t}}-d$ dependency with 1.6 $\left(1 /\left(K \cdot s^{1 / 2}\right)\right)$ threshold value for the experimental data. The linear dependence equation for the coating thickness dependence on the threshold time has been obtained by linear fitting in the form:

$\mathrm{d}=0.1+0.9 \sqrt{t_{t}}$ 


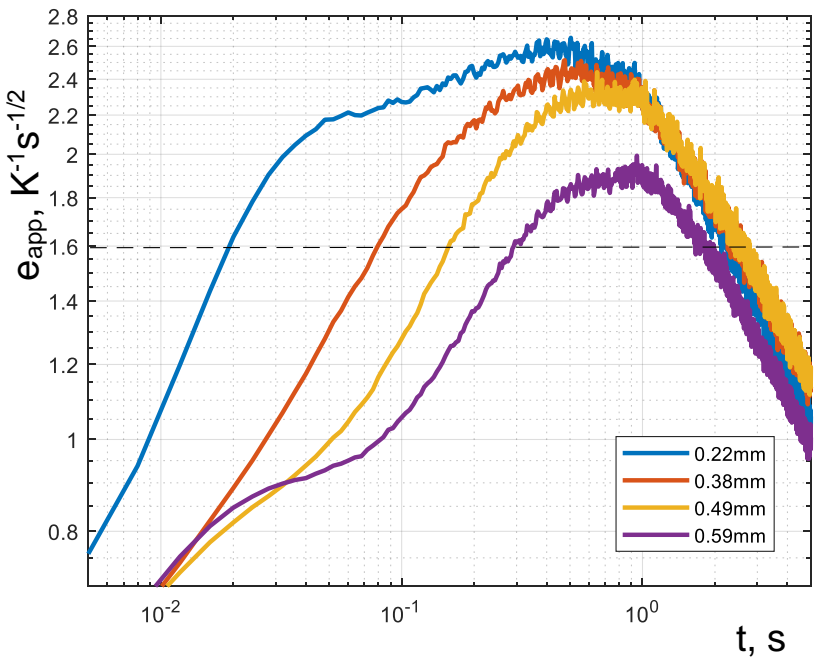

a)

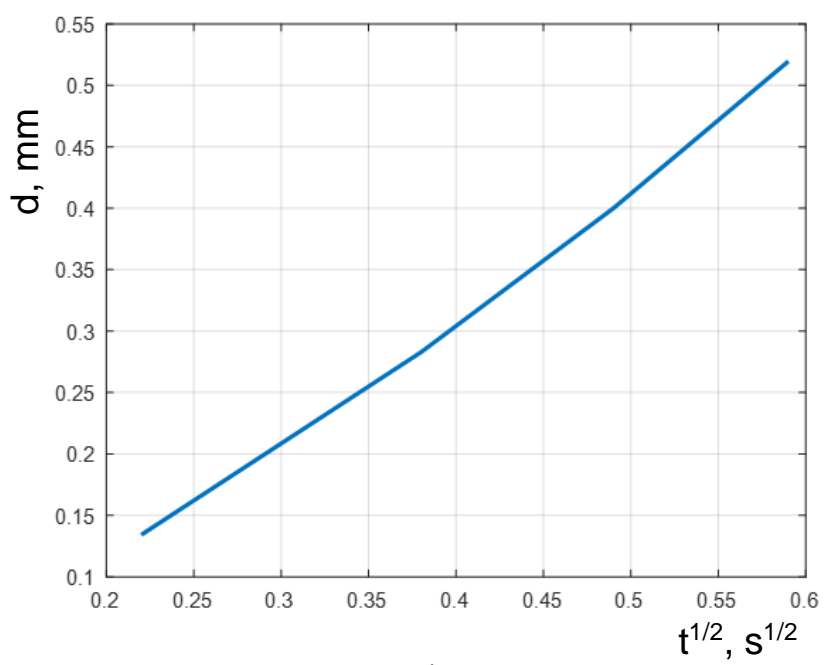

b)

Figure 2 Experimental apparent effusivity curves (a) and $\sqrt{t_{t}}-d$ dependency (b)

Subsequently, using the above described procedure the infrared contour image in (Figure $\mathbf{3}$ a) can be transformed to a coating thickness variations contour image presented in (Figure $\mathbf{3} \mathbf{~ b}$ ).

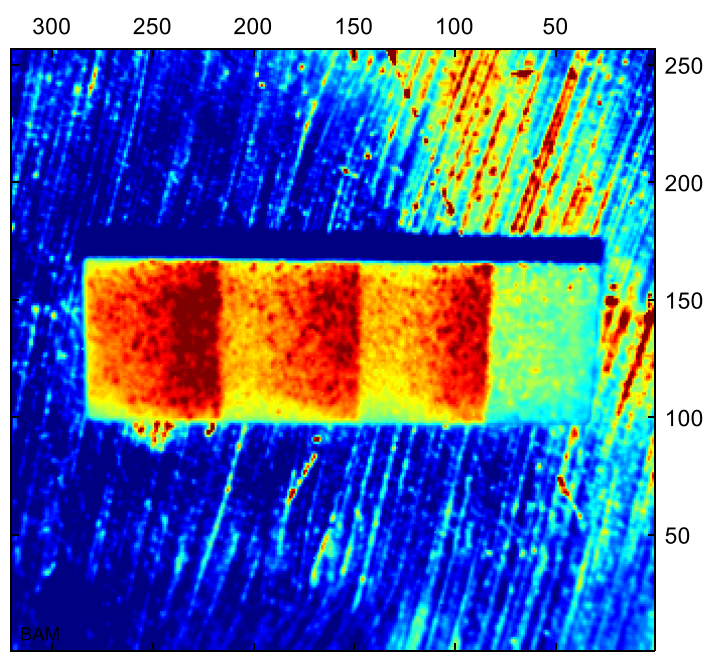

a)

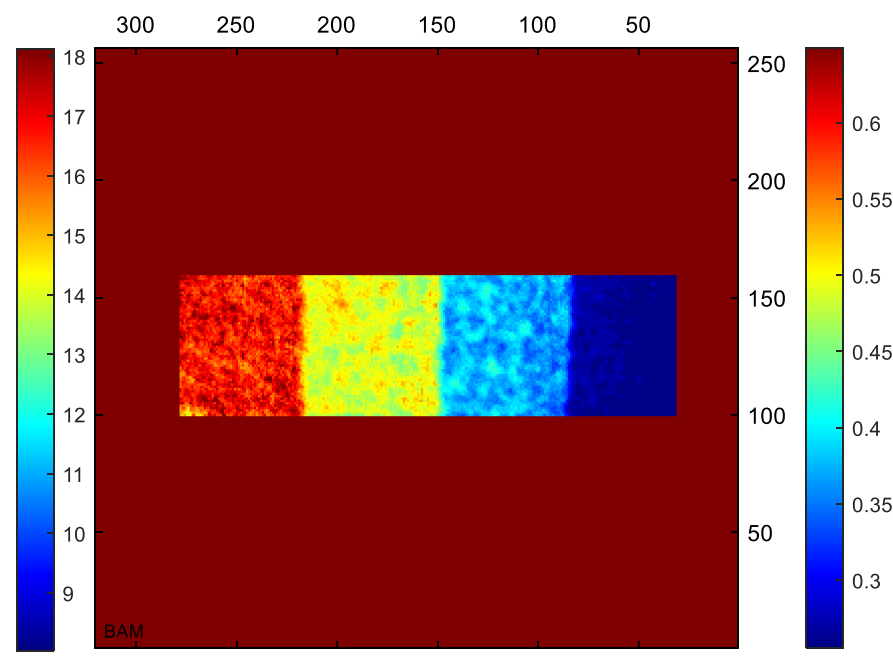

b)

Figure 3 Thermogram (relative temperatures contour image) at the time $0.012 \mathrm{~s}$ after the flash pulse (a) and a map of coating thickness (b).

\section{CONCLUSION}

The contribution describes a flash thermography technique intended for the determination of coating thickness based on the apparent thermal effusivity concept and threshold observation time. Unlike other approaches, for example, those using an inflection point in the apparent effusivity evolution curve, the threshold observation time was defined as a crossing point of the apparent thermal effusivity curve and a pre-defined effusivity threshold. An important advantage of this method is also a linear dependence between the square root of the threshold time and coating thickness. Hence, only two reference thicknesses are required to create calibration dependency. It allows to produce 2D distributions of absolute coating thickness, as well as its variations. This linear dependence was predicted by the theoretical analysis and subsequently confirmed by the experimental data on $\mathrm{Cr} 13 \% \mathrm{Fe}$ coatings deposited on steel substrates using the TWAS thermal spraying technology. It was 
confirmed that the suggested method resolution is sufficient to show difference between thickness of these coatings in the range from 0.22 to $0.59 \mathrm{~mm}$. The suggested technique is also simple to use and robust enough for practical applications. The only limitation is the fact that the thermal properties of the substrate and coating should be significantly different. It is essential for all thermal methods.

\section{ACKNOWLEDGEMENTS}

This research was founded by ERDF project "LABIR-PAV/Pre-application research of infrared technologies" Reg. No. CZ.02.1.01/0.0/0.0/18_069/0010018 and by the project SGS-2019-008.

\section{REFERENCES}

[1] PARKER, G. Guide-Wave Optical Communications: Materials. Encyclopedia of materials: science and technology. 2001, pp. 3703-3707.

[2] KUTZ, M. Handbook of environmental degradation of materials. William Andrew, 2018

[3] GARCÍA-MARTÍN, J., GÓMEZ-GIL, J., VÁZQUEZ-SÁNCHEZ, E. (2011). Non-destructive techniques based on eddy current testing. Sensors, 2013, vol. 11, no. 3, pp. 2525-2565.

[4] RUSSE, I. S., BROCK, D., KNOP, K., KLEINEBUDDE, P., \& ZEITLER, J. A. (2012). Validation of terahertz coating thickness measurements using X-ray microtomography. Molecular Pharmaceutics. 2012, vol. 9, no. 12, pp 3551-3559.

[5] MALDAGUE, X. Theory and practice of infrared technology for nondestructive testing. New-York: Wiley, 2001.

[6] VAVILOV, V. P., BURLEIGH, D. D. Review of pulsed thermal NDT: Physical principles, theory and data processing. Ndt \& E International. 2015, vol. 73, pp. 28-52.

[7] SHRESTHA, R., KIM, W. Evaluation of coating thickness by thermal wave imaging: A comparative study of pulsed and lock-in infrared thermography-Part I: Simulation. Infrared Physics \& Technology. 2017, vol. 83, pp. 124-131.

[8] TANG, Q., LIU, J., DAI, J., YU, Z. Theoretical and experimental study on thermal barrier coating (TBC) uneven thickness detection using pulsed infrared thermography technology. Applied Thermal Engineering. 2017, vol. 114, pp. 770-775.

[9] RANJIT, S., CHUNG, Y., KIM, W. Thermal behavior variations in coating thickness using pulse phase thermography. Chinese characters. 2016, vol. 36, no. 4, pp. 259-265.

[10] ZHAO, S. B., ZHANG, C. L., WU, N. M., WANG, H. M. Quality evaluation for air plasma spray thermal barrier coatings with pulsed thermography. Progress in Natural Science: Materials International. 2011, vol. 21, no. 4, pp. 301-306.

[11] ŠVANTNER, M., MUZIKA, L., HOUDKOVÁ, Š. Quantitative inspection of coatings thickness by time-power transformation flash pulse thermographic method. In Multidisciplinary Digital Publishing Institute Proceedings. 2019, vol. 27, no. 1, p. 32.

[12] CERNUSCHI, F., MARINETTI, S. Discrimination between over-thickness and delamination of thermal barrier coatings by apparent thermal effusivity thermographic technique. Journal of thermal spray technology. 2010, vol. 19, no. 5, pp. 958-963.

[13] MARINETTI, S., ROBBA, D., CERNUSCHI, F., BISON, P. G., GRINZATO, E. Thermographic inspection of TBC coated gas turbine blades: Discrimination between coating over-thicknesses and adhesion defects. Infrared physics \& technology. 2007, vol. 49, no. 3, pp. 281-285.

[14] BOUÉ, C., FOURNIER, D. Infrared thermography measurement of the thermal parameters (effusivity, diffusivity and conductivity) of materials. Quantitative InfraRed Thermography Journal. 2009, vol. 6, no. 2, pp. 175-188.

[15] ARIZMENDI-MORQUECHO, A., CAMPA-CASTILLA, A., LEYVA-PORRAS, C., AGUILAR MARTINEZ, J. A., VARGAS GUTIÉRREZ, G., MORENO BELLO, K. J., LÓPEZ LÓPEZ, L. Microstructural characterization and wear properties of Fe-based amorphous-crystalline coating deposited by twin wire arc spraying. Advances in Materials Science and Engineering. 2014. 